\title{
Multivariate Regression Analysis Identifying
}

\section{Predictors of Patient Satisfaction with Multifocal IOLs: $+4.00 /+4.00$ vs $+3.25 /+3.25$ vs $+3.25 /$ EDOF}

This article was published in the following Dove Press journal: Clinical Ophthalmology

Frank A Bucci Jr

Bucci Laser Vision, Institute WilkesBarre, Wilkes-Barre, PA, USA
Correspondence: Frank A Bucci Jr Bucci Laser Vision Institute, I58 WilkesBarre Township Blvd.,Wilkes-Barre, PA 18702, USA

Email buccivision@aol.com
Purpose: To detect and compare the predictors of "overall patient satisfaction" with an $\mathrm{EDOF} /+3.25$ versus $+3.25 /+3.25$ versus $+4.00 /+4.00$ diffractive multifocal IOLs.

Setting: Bucci Laser Vision Institute, Wilkes-Barre, PA, USA.

Design: Non-interventional, observational, retrospective-prospective.

Patients and Methods: A total of $55(\mathrm{EDOF} /+3.25)$ "best case patients" with 1) 4 months neuroadaptation 2) corrected residual refractive error 3) necessary YAGs performed and 4) aggressive ocular surface management underwent regression analysis to identify predictors of "overall patient satisfaction". Satisfaction was regressed against 40 independent variables 31 clinical metrics such as reading speed and acuity, angle kappa, aberrations, mesopic pupil size, residual spherical equivalent and astigmatism, near, intermediate vision at fixed and preferred focal distances, etc., and 9 responses from a questionnaire evaluating the performance of everyday tasks. Results were compared to two prior cohorts $(67$ bilateral +3.25 and 55 bilateral +4.00$)$ with identical methods.

Results: Eighty percent (44/55) of the EDOF/ +3.25 patients were "very satisfied" and $20 \%(11 / 55)$ were "satisfied" compared to $82 \%$ "very satisfied"/18\% "satisfied" $(+3.25 /+3.25)$ and $64 \%$ "very satisfied"/36\% "satisfied" $(+4.00 /+4.00)$. Subjective scores for near VA $(\mathrm{p}=0.02)$ were in favor of the $+3.25 /+3.25(1.92 / 2.00)$ vs EDOF/3.25 (1.76/2.00). However, EDOF/+3.25 scores for intermediate VA (4.65/5.00 vs 4.32/5.00; $\mathrm{p}=0.02)$ and distance VA (4.76/5.00 vs 4.53/5.00; $\mathrm{p}=0.047)$ were significantly better than bilateral +3.25 and bilateral +4.00 . In the bilateral +3.25 cohort, regression revealed that variables related to intermediate vision were responsible for outperforming the bilateral +4.00 cohort, and it also showed that smaller mesopic pupils $(\mathrm{p}=0.005)$ again predicted better intermediate vision as was observed in the bilateral +4.00 patients.

Conclusion: The EDOF/ +3.25 patients had equal patient satisfaction vs the bilateral +3.25 , and greater satisfaction vs the bilateral +4.00 patients because of significantly better intermediate and distance vision, despite scoring less for near vision with fine print and no difference with moderate print. Regression predicted better intermediate vision with smaller mesopic pupils with the +3.25 and +4.00 IOLs.

Keywords: presbyopia, multifocal, extended depth of focus, patient satisfaction, cataract, regression analysis

\section{Introduction}

Reading and performing tasks at near is an important part of daily life.

The progressive development of presbyopia-correcting intraocular lenses (IOLs) and an aging population has increased the demand and opportunity for spectacle independence in patients undergoing cataract surgery. Multifocal and extended 
depth of focus (EDOF) implants can provide functional uncorrected vision at near and intermediate distances resulting in high levels of satisfaction in the majority of patients. $^{1-3}$

There are, however, limitations of presbyopiccorrecting IOLs that can lead to less than optimal patient satisfaction including loss of contrast sensitivity, dysphotopsias, ${ }^{4}$ and an inability to achieve acceptable functional outcomes for all three visual targets - distance, intermediate, and near.

Evaluating patient satisfaction can be challenging because the subjective perception of each patient to an identical objective stimulus, like an IOL, can be highly variable. Kohnen ${ }^{3}$ has emphasized that although objective scientific measures will always dominate our assessment of visual outcomes, we cannot underestimate the patients' subjective perception of their quality of vision when assessing our surgical results. Cultural, psychological, and emotional factors can significantly influence the patients' perception of their visual and functional outcomes.

The primary purpose of this study was to use a multivariate regression model to evaluate which objective and/or subjective characteristics contributed significantly to patient responses regarding "overall patient satisfaction". The purpose was not just to quantitate the levels of overall patient satisfaction, but also to determine "why" the patients achieved various levels of satisfaction or dissatisfaction (for each of the 3 cohorts studied). The multivariate regression model contained 40 independent variables that were regressed against the dependent variable "overall patient satisfaction". The 40 independent variables included 31 objective clinical metrics (10 preoperative and 21 postoperative) and the subjective response to nine questions from a patient questionnaire.

\section{Patients and Methods Study Design}

This retrospective-prospective, single-center, nonrandomized, comparative, three-armed study consecutively enrolled sequential bilateral cataract surgery patients into three cohorts. Patients received either two +4.00 TECNIS Multifocal IOLs (ZMB00; Johnson \& Johnson Vision, Jacksonville, FL, USA), two +3.25 TECNIS Multifocal IOLs (ZLB00; Johnson \& Johnson) or one +3.25 TECNIS Multifocal IOL (ZLB00) and one TECNIS Symfony extended range of vision IOL (ZXR00; Johnson
\& Johnson) or a TECNIS Symfony Toric (ZXT150, ZXT225, and ZXT375; Johnson \& Johnson).

The last preoperative visit and the cataract surgery were reviewed retrospectively, and the final postoperative evaluation was documented prospectively. The study was approved by an independent institutional review board (2018.03.30, Salus IRB, Austin, TX, USA). Written informed consent was obtained from each patient prior to enrollment. The principles of Good Clinical Practice were adhered to in accordance with the Declaration of Helsinki and its subsequent revisions.

Inclusion criteria included (1) at least 4 months of neuroadaptation (2) all necessary YAG laser capsulotomies performed (3) residual refractive error corrected to $\leq 0.5 \mathrm{D}$ of spherical and cylinder error, and (4) a wellmanaged ocular surface. Strict exclusion criteria were adhered to in an effort to minimize the influence of external factors on detecting predictors of overall patient satisfaction by multiple regression analysis. The goal was to isolate the function of the presbyopic correcting IOLs and avoid other influences on visual function. Ocular comorbidities that might decrease postoperative visual outcomes such as mild to moderate macular thickening, epiretinal membranes, irregular astigmatism, corneal endothelial dystrophy, or mild amblyopia would exclude patients from enrollment.

\section{Patients}

All patients completed a comprehensive preoperative ophthalmologic examination including optical biometry, aberrometry, topography, optical coherence tomography, and pachymetry. Patients in the $+4.00 /+4.00$ cohort underwent surgery prior to February 2015 when low add multifocal IOLs were unavailable in the US. Patients in the $+3.25 /+3.25$ cohort completed surgery after February 2015 and prior to January 2017. Patients in the Symfony/+3.25 cohort completed surgery between July 2016 and September 2018.

Patient selection for presbyopic correcting IOL cataract surgery and the specific IOLs chosen were based on the objective ocular characteristics and subjective visual needs and preferences of the patients. Patients received whichever IOLs were commercially available that, in the opinion of the surgeon, would maximize patient satisfaction. All surgeries were performed by the same experienced surgeon (FAB). The independent variables isolated at the preoperative examination that were regressed against "overall patient satisfaction" are 


\section{Box I Preoperative Clinical Metrics}

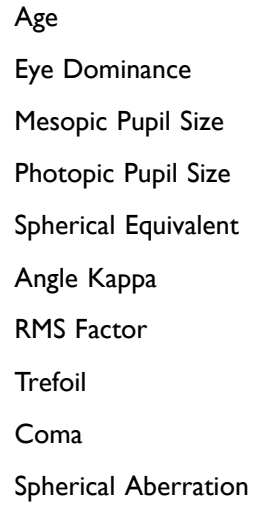

\section{Box 2 Postoperative Clinical Metrics}

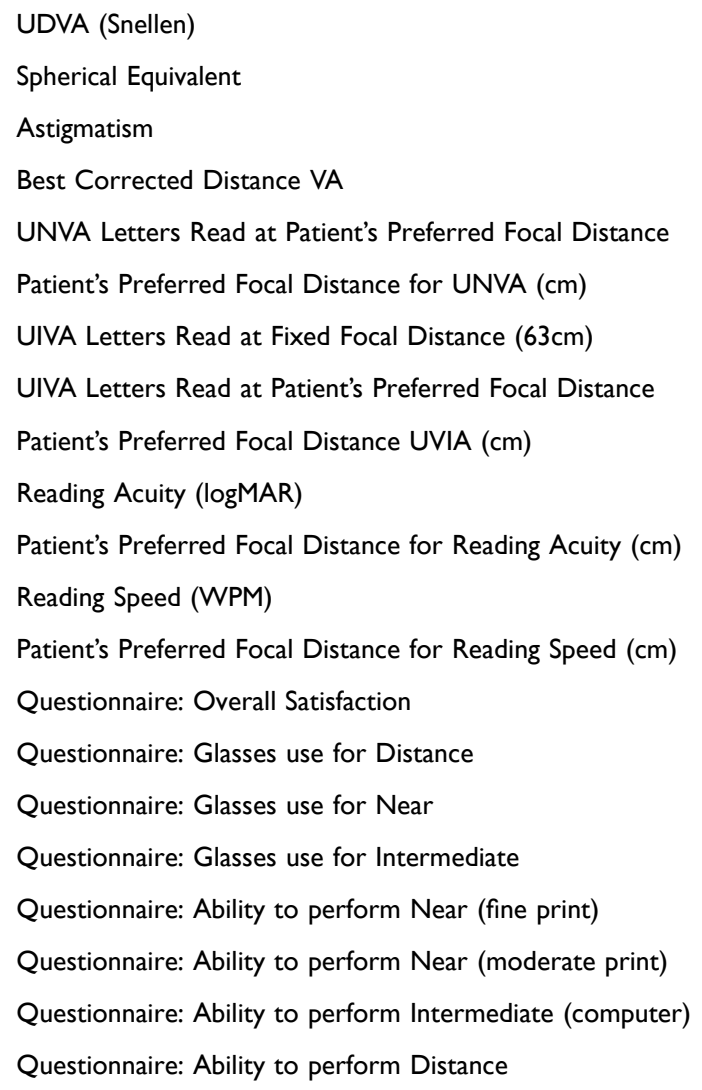

listed in Box 1. The independent postoperative clinical metrics regressed against "overall patient satisfaction" are listed in Box 2.

The subjective patient satisfaction questionnaire, which recorded the patient's responses to nine questions, is presented in Table 1. The first question quantifies the responses for the independent variable of "overall patient satisfaction". The study targets the bilateral results for each cohort and the influence of each preoperative and postoperative variable on the subjective levels of "overall patient satisfaction". Multivariate regression analysis detected which variables are statistically significant predictors of patient responses regarding the independent variable of "overall patient satisfaction". Patients underwent a final, comprehensive postoperative visit at which their postoperative objective metrics and subjective questionnaire data were collected. A minimum of 4 months (and no greater than 8 months) of neuroadaptation was required before the final, comprehensive postoperative visit was completed.

At the comprehensive postoperative study visit, UDVA, BCVA, and manifest refraction were performed using a standard ETDRS chart. Near and intermediate visions at fixed focal lengths were tested using the Colenbrander Mixed Contrast Card (Precision Vision, Woodstock, IL, USA) at a reading distance of $40 \mathrm{~cm}$ and a computer distance of $63 \mathrm{~cm}$. The MNREAD Acuity Chart (Precision Vision) was used to test reading acuity (logMAR) and reading speed (words per minute). Lens centration was graded by the surgeon postoperatively on a scale from 1 to 10 .

\section{Intraocular Lenses}

The TECNIS ZMB00 and ZLB00 (Johnson \& Johnson Vision) are diffractive bifocal 1-piece hydrophobic acrylic IOLs with a full diffractive posterior surface, an anterior aspheric surface, and a $+4.00 \mathrm{D}$ add and a $+3.25 \mathrm{D}$ add, respectively, at the IOL plane. The overall IOL length for both designs is $13.0 \mathrm{~mm}$ with an optic diameter of $6.0 \mathrm{~mm}$. The design of both the TECNIS +4.00 (ZMB00) and the TECNIS +3.25 (ZLB00) IOLs includes a central $1.00 \mathrm{~mm}$ zone with half the add power of the full add, which is capable of assisting the patient with intermediate vision.

The TECNIS Symfony (ZXR00; Johnson \& Johnson) and TECINS Symfony Toric (ZXT150, ZXT225, and ZXT375) are 1-piece hydrophobic acrylic biconvex extended range of vision IOLs. The design incorporates a proprietary aspheric $(-0.27 \mu \mathrm{m})$ or toric-aspheric anterior surface and a posterior surface with a $5.5 \mathrm{~mm}$ achromatic diffractive pattern that increases the depth of focus and compensates for chromatic aberration. The diffractive design incorporates a unique echelette feature with a pupil-independent lens performance in any lighting condition. 
Table I Patient Satisfaction Survey

\begin{tabular}{|c|c|c|}
\hline \multicolumn{3}{|c|}{ I. In general, how satisfied have you been with your OVERALL VISUAL FUNCTION without glasses? } \\
\hline $\begin{array}{l}\text { Please check one: } \\
\square \text { No Difference }\end{array}$ & $\begin{array}{l}\square \text { Very Satisfied } \\
\square \text { Dissatisfied }\end{array}$ & $\begin{array}{l}\square \text { Satisfied } \\
\square \text { Very dissatisfied }\end{array}$ \\
\hline \multicolumn{3}{|c|}{ 2. In general, how often each day do you use glasses for DISTANCE VISION? (TV, driving, etc.) } \\
\hline $\begin{array}{l}\text { Please check one: } \\
\square \text { Half of the time }\end{array}$ & $\begin{array}{l}\square \text { None of the time } \\
\square \text { Most of the time }\end{array}$ & $\begin{array}{l}\square \text { Some of the time } \\
\square \text { All of the time }\end{array}$ \\
\hline \multicolumn{3}{|c|}{ 3. In general, how often each day do you use glasses for NEAR VISION? (reading a book or newspaper) } \\
\hline $\begin{array}{l}\text { Please check one: } \\
\square \text { Half of the time }\end{array}$ & $\begin{array}{l}\square \text { None of the time } \\
\square \text { Most of the time }\end{array}$ & $\begin{array}{l}\square \text { Some of the time } \\
\square \text { All of the time }\end{array}$ \\
\hline \multicolumn{3}{|c|}{ 4. In general, how often each day do you use glasses for INTERMEDIATE VISION? (arms length activity, like the computer) } \\
\hline $\begin{array}{l}\text { Please check one: } \\
\square \text { Half of the time }\end{array}$ & $\begin{array}{l}\square \text { None of the time } \\
\square \text { Most of the time }\end{array}$ & $\begin{array}{l}\square \text { Some of the time } \\
\square \text { All of the time }\end{array}$ \\
\hline \multicolumn{3}{|c|}{ 5. Please rate your ability to perform the following activities without glasses: } \\
\hline $\begin{array}{l}\text { Reading small print (phonebook or drug package insert): } \\
\square \text { Good }\end{array}$ & $\begin{array}{l}\square \text { Excellent } \\
\square \text { Fair }\end{array}$ & $\begin{array}{l}\square \text { Very Good } \\
\square \text { Poor }\end{array}$ \\
\hline \multicolumn{3}{|c|}{ 6. Please rate your ability to perform the following activities without glasses: } \\
\hline $\begin{array}{l}\text { Reading the newspaper: } \\
\square \text { Good }\end{array}$ & $\begin{array}{l}\square \text { Excellent } \\
\square \text { Fair }\end{array}$ & $\begin{array}{l}\square \text { Very Good } \\
\square \text { Poor }\end{array}$ \\
\hline \multicolumn{3}{|c|}{ 7. Please rate your ability to perform the following activities without glasses: } \\
\hline $\begin{array}{l}\text { Working on a computer (arms length activity): } \\
\square \text { Good }\end{array}$ & $\begin{array}{l}\square \text { Excellent } \\
\square \text { Fair }\end{array}$ & $\begin{array}{l}\square \text { Very Good } \\
\square \text { Poor }\end{array}$ \\
\hline \multicolumn{3}{|c|}{ 8. Please rate your ability to perform the following activities without glasses: } \\
\hline $\begin{array}{l}\text { Seeing objects far away: } \\
\square \text { Good }\end{array}$ & $\begin{array}{l}\square \text { Excellent } \\
\square \text { Fair }\end{array}$ & $\begin{array}{l}\square \text { Very Good } \\
\square \text { Poor }\end{array}$ \\
\hline \multicolumn{3}{|c|}{$\begin{array}{l}\text { 9. If given the opportunity, would you again choose to pay out of pocket to have surgery with multifocal implants, which allow you to read withou } \\
\text { glasses, or would you elect to pay less money and receive the implants that do not allow you to read without glasses? } \\
\square \text { I would still elect to receive the same multifocal implants } \\
\square \text { I would accept implants that do not enable me to read without glasses }\end{array}$} \\
\hline
\end{tabular}

\section{Statistical Analysis}

RStudio Version 1.1.463 with R Commander Version 2.5-1 and the MASS Library (R Studio, Boston, MA, USA) was used to perform stepwise multiple backward/forward regressions based on the AIC (Akaike Information Criterion). Stepwise forward/backward AIC was used first to produce a subset of potential independent predictor variables upon which manual stepwise backward elimination evaluation of nested models was performed to arrive at a final model. Standardized regression coefficients (Beta weights) were calculated and reported for the final model along with adjusted $\mathrm{R}$-squared, the fraction of the variance explained by the model.
A non-parametric (distribution-free) independent-samples Mann-Whitney $U$-test was performed using the variables and statistical significance was defined as a $p$-value of $<0.05$.

A $t$-test for the comparison of the means of independent samples was performed. This procedure calculated the difference between the observed means of two independent samples. When the calculated p-value was less than 0.05 $(\mathrm{P}<0.05)$, the two means were significantly different.

\section{Results}

The demographics for the three cohorts studied are presented in Table 2. 
Table 2 Demographic Characteristics

\begin{tabular}{|c|l|l|l|}
\hline Parameter & $\begin{array}{l}\mathbf{+ 4 . 0 0 / + 4 . 0 0} \\
(\mathbf{n = 5 5 )}\end{array}$ & $\begin{array}{l}\mathbf{+ 3 . 2 5 / + 3 . 2 5} \\
(\mathbf{n}=66)\end{array}$ & $\begin{array}{l}\mathbf{+ 3 . 2 5 / E D O F} \\
(\mathbf{n}=55)\end{array}$ \\
\hline $\begin{array}{c}\text { Age } \\
\text { Mean } \pm \text { SD }\end{array}$ & $\begin{array}{l}65.15 \pm 8.79 \\
\text { Min, Max }\end{array}$ & $\begin{array}{l}62,82.14 \pm 9.11 \\
45,86\end{array}$ & $\begin{array}{l}61.69 \pm 7.77 \\
44,81\end{array}$ \\
\hline $\begin{array}{c}\text { Sex, n (\%) } \\
\text { Male }\end{array}$ & $27(49 \%)$ & $27(41 \%)$ & $12(22 \%)$ \\
Female & $28(51 \%)$ & $39(59 \%)$ & $43(78 \%)$ \\
\hline
\end{tabular}

\section{Bilateral \pm 4.00 D Cohort}

The subjective patient questionnaire for the $+4.00 /+4.00$ cohort revealed that $64 \%$ of patients chose "very satisfied" and 36\% choose "satisfied" for the "overall patient satisfaction" question (Table 3). Multiple regression analysis, in general, revealed that variables related to intermediate vision significantly influenced patients' decisions regarding their overall satisfaction (Figure 1). Regression detected three of the 40 independent variables as contributing significantly to the dependent variables of "overall patient satisfaction" $\left(\mathrm{R}^{2}=0.57\right)$. Two of the three variables are directly related to intermediate vision: "working on a computer" $(p<0.05)$ and "intermediate vision at preferred focal length" $(\mathrm{p}=0.005)$. Both variables in the equation have positive coefficients indicating a positive correlation with "overall patient

\section{"Overall Patient Satisfaction" =}

+2.37 (constant)

+.30 newspaper

$\mathrm{p}<.005$

+.18 computer

$p<.005$

+.08 intermediate

$p=.05$

(preferred focal distance)

$\mathrm{R}^{2}=.57$

Figure I +4.00/+4.00 Multivariate Regression.

satisfaction". "Reading the newspaper" as compared to "reading fine print" is considered to be at least indirectly related to intermediate vision because of the high variability in the focal distance chosen by patients when they read the newspaper.

The results from the initial regression equation allowed us to further explore our findings with bivariate analysis that couples all 40 independent variables into every possible combination to detect potential correlations. Strong generalized correlations were detected between intermediate vision (both fixed and preferred focal lengths) variables and variables related to pupil size (both photopic and mesopic). At this juncture, the science of statistics supports the creation of another

Table 3 Results of Subjective Patient Questionnaire

\begin{tabular}{|c|c|c|c|c|c|c|}
\hline \multirow[t]{2}{*}{ Parameter } & \multicolumn{3}{|l|}{ Mean \pm SD } & \multicolumn{3}{|l|}{$P$ value } \\
\hline & $+4.00 /+4.00$ & $+3.25 /+3.25$ & $+3.25 /$ EDOF & $\begin{array}{l}+4.00 /+4.00 \text { vs } \\
+3.25 /+3.25\end{array}$ & $\begin{array}{l}+4.00 /+4.00 \text { vs } \\
+3.25 / \text { EDOF }\end{array}$ & $\begin{array}{l}+3.25 /+3.25 \text { vs } \\
+3.25 / \text { EDOF }\end{array}$ \\
\hline $\begin{array}{l}\text { Overall Satisfaction (visual } \\
\text { function without glasses) }{ }^{\mathrm{a}}\end{array}$ & $1.63 \pm 0.487$ & $1.82 \pm 0.462$ & $1.80 \pm 0.404$ & $0.0307^{*}$ & $0.0504 *$ & 0.8040 \\
\hline $\begin{array}{l}\text { Frequency of glasses use - } \\
\text { Distance }^{\text {b }}\end{array}$ & $1.98 \pm 0.136$ & $1.98 \pm 0.123$ & $1.98 \pm 0.135$ & 1.00 & 0.4931 & 0.4485 \\
\hline Frequency of glasses use - Near & $1.94 \pm 0.231$ & $1.92 \pm 0.404$ & $1.76 \pm 0.576$ & 0.7473 & $<0.000 I^{*}$ & $<0.0001 *$ \\
\hline $\begin{array}{l}\text { Frequency of glasses use - } \\
\text { Intermediate }\end{array}$ & $1.87 \pm 0.584$ & $1.83 \pm 0.597$ & $1.96 \pm 0.189$ & 0.7130 & 0.2610 & 0.1137 \\
\hline $\begin{array}{l}\text { Ability to read small print } \\
\text { (phonebook) without glasses } \dagger\end{array}$ & $4.20 \pm 0.73663$ & $4.00 \pm 0.96775$ & $3.82 \pm 1.07309$ & $0.146 \mid$ & $0.0232 *$ & 0.057 \\
\hline $\begin{array}{l}\text { Ability to read newspaper } \\
\text { without glasses }\end{array}$ & $4.444 \pm 0.6914$ & $4.439 \pm 0.7260$ & $4.42 \pm 0.7895$ & 0.9695 & 0.7961 & 0.8178 \\
\hline $\begin{array}{l}\text { Ability to work on computer } \\
\text { without glasses }\end{array}$ & $3.91 \pm 1.0947$ & $4.32 \pm 0.8949$ & $4.65 \pm 0.5517$ & $0.02 *$ & $0.0001 *$ & $0.002 *$ \\
\hline $\begin{array}{l}\text { Ability to see far away without } \\
\text { glasses }\end{array}$ & $4.44 \pm 0.69137$ & $4.53 \pm 0.78876$ & $4.76 \pm 0.46997$ & 0.5125 & $0.006 *$ & $0.047^{*}$ \\
\hline
\end{tabular}

Notes: ${ }^{2}$ Overall satisfaction scale: +2 Very Satisfied, + I Satisfied, 0 No Difference, -1 Dissatisfied, -2 Very dissatisfied. ${ }^{b}$ Frequency scale: +2 None of the time, $+\mid$ Some of the time, 0 Half of the time, -1 Most of the time, -2 All of the time. ${ }^{\dagger}$ Ability scale: 5 Excellent, 4 Very Good, 3 Good, 2 Fair, I Poor. *Statistical significance defined as p<0.05. 
Intermediate (pref. focal) $=$

+112.87 (constant)

- 2.89 mesopic pupil

- 5.01 centration (IOL)

$\mathrm{R}^{2}=.24$

Figure $2+4.00 /+4.00$ Multivariate Regression

regression analysis with "intermediate vision" being the new dependent variable. Two independent variables were detected as contributing significantly to the outcomes of "intermediate vision at preferred focal length" (Figure 2). "Mesopic pupil size" and "lens centration" both had negative coefficients in the equation with an $\mathrm{R}^{2}$ $=0.24$. This equation tells us that as mesopic pupil size decreases, intermediate vision increases. As stated in methods, centration was graded postoperatively by the surgeon on a scale from 1 to 10 with 1 being the best centration. As the numerical centration grade decreased, the quality of the "intermediate vision at preferred focal length" increases.

\section{Bilateral \pm 3.25 Cohort}

The patient questionnaire for the $+3.25 /+3.25$ cohort $(n=67)$ revealed that $82.0 \%$ of the patients chose "very satisfied" and $18 \%$ chose "satisfied" for the "overall patient satisfaction" question (Table 3). The increase in the "very satisfied" level of "overall patient satisfaction" from $64 \%$ to $82 \%$ compared to the $+4.00 /+4.00$ cohort was statistically $(\mathrm{p}=0.01)$ and clinically significant.

The increased overall satisfaction of the $+3.25 /+3.25$ cohort is very likely due to the statistically significant increase with intermediate vision compared to the +4.00 / +4.00 cohort. The focal length for the +3.25 multifocal IOL is $42 \mathrm{~cm}$ compared to $33 \mathrm{~cm}$ for the +4.00 multifocal IOL. The grade of "excellent" for the "working on a computer" (arm's length activity) variable increased from $38 \%$ with the $+4.00 /+4.00$ patients to $55 \%(\mathrm{p}=0.02)$ for the $+3.25 /+3.25$ patients (Table 3 ). These results are consistent with an increased focal length of $42 \mathrm{~cm}$ for the +3.25 IOL compared to the $33 \mathrm{~cm}$ of the +4.00 IOL.

The design of the +3.25 TECNIS multifocal IOL, with a $1.00 \mathrm{~mm}$ central zone having half the power of the full ad, would predict that patients with smaller pupils would again demonstrate superior intermediate vision. Or does the "working on a computer" =

+6.29 (constant)

- 4.04 mesopic pupil $\quad p=.0005$

"frequency of glasses use for intermediate vision" = +3.63 constant

-.375 mesopic pupil size $\quad p=.005$

Figure $3+3.25 /+3.25$ Multiple Regression Analysis.

increased focal length to $42 \mathrm{~cm}$ of the +3.25 IOL "wash out" this optical effect? Regression analysis detected a statistically significant contribution of mesopic pupil size to the outcomes for two key variables related to intermediate vision (Figure 3). "Working on a computer" $(\mathrm{p}=0.0005)$ and "frequency of glasses use for intermediate vision" $(\mathrm{p}=0.005)$ both had negative coefficients indicating that this visual function significantly increased as the mesopic pupil size decreased. The preoperative pupil size was again shown to be a meaningful predictor of postoperative uncorrected intermediate visual function as seen with the $+4.00 /+4.00$ cohort.

In addition to the superior performance with intermediate vision, the data for near vision also support the greater satisfaction observed with the bilateral +3.25 cohort versus the bilateral +4.00 cohort. Table 3 reveals no significant difference in the mean scores for "reading fine print (phonebook)" between the two cohorts. There is also little difference between the percentages of patients reporting a score of "excellent" ( $36 \%$ vs $34 \%$ ) for this variable. Achieving significantly better uncorrected intermediate vision, while essentially maintaining equivalent near vision when moving from a higher add multifocal to a lower add multifocal, supports the findings of better overall satisfaction for the bilateral +3.25 IOL cohort compared to the bilateral +4.00 cohort.

\section{EDOF/ \pm 3.25 Cohort}

The patient questionnaire for the EDOF/ +3.25 cohort $(n=55)$ revealed that $80.0 \%$ of the patients choose "very satisfied" and $20.0 \%$ choose "satisfied" for the "overall patient satisfaction" question (Table 3). There was no significant difference for "overall patient satisfaction" question compared to the $+3.25 /+3.25$ cohort and it was significantly improved $(\mathrm{p}=0.01)$ compared to the $+4.00 /$ +4.00 cohort.

Multiple regression analysis showed that the patient answers for the "overall patient satisfaction" variable were strongly influenced by their performance with near 
"Overall Patient Satisfaction"

+1.73 (constant)

- 1.69 post-op Reading Acuity

- 1.40 pre-op Spherical Aberration

$p=0.00057$

$p=0.036$

Figure 4 EDOF/+3.25 Multiple Regression Analysis.

vision (Figure 4). The mean score for "reading fine print" dropped to $3.82 / 5.00$ and was significantly less than the $+4.00 /+4.00$ cohort $(\mathrm{p}=0.02)$ and was almost significantly less than the $+3.25 /+3.25$ cohort with a strong trend in that direction $(\mathrm{p}=0.057)$. The grade of excellent was only $25.0 \%$ for the EDOF/ +3.25 cohort compared to the $37.0 \%$ and $34.0 \%$ of the $+4.00 /+4.00$ and $+3.25 /+3.25$ cohorts, respectively. The variable of "frequency of glasses use at near" revealed similar results (Figure 5).

How can the "overall patient satisfaction" scores be equivalent for the latter two cohorts if the uncorrected near vision is significantly less efficient for the $\mathrm{EDOF} /+3.25$ patients versus the bilateral +3.25 patients? A close look at the results for intermediate and distance vision suggests an explanation.

The subjective patient scores for the variable of the "ability to work on a computer," which strongly corresponds to intermediate vision, are significantly better in the EDOF/ +3.25 cohort compared to both other cohorts (Figure 6). The raw score on the questionnaire was $4.65 \pm 0.55$ out of 5.00 compared to $4.32 \pm 0.89$ (bilateral +3.25 ) and $3.91 \pm 1.10$ (bilateral +4.00). The rank of "excellent" increased to $65 \%$ for the $\mathrm{EDOF} /+3.25$ compared to $55 \%$ (bilateral +3.25 ) and $38 \%$ (bilateral +4.00 ) for the other two cohorts. Figure 7 reports the data for the variable "ability to see far away" and reveals significantly better uncorrected distance vision in the EDOF/ +3.25 cohorts compared to both the bilateral +3.25 cohort $(\mathrm{p}=0.047)$ and the bilateral +4.00 cohort $(\mathrm{p}=0.006)$.

The results for the variable of "arm length activity (computer)" (Figure 6) clearly demonstrated superior intermediate visual function for the $\mathrm{EDOF} /+3.25$ cohort. The mean score in the EDOF/ +3.25 cohort for "arm's length activity" was $4.65 / 5.00$ compared to $4.32 / 5.00$

"Frequency of Glasses Use at Near"

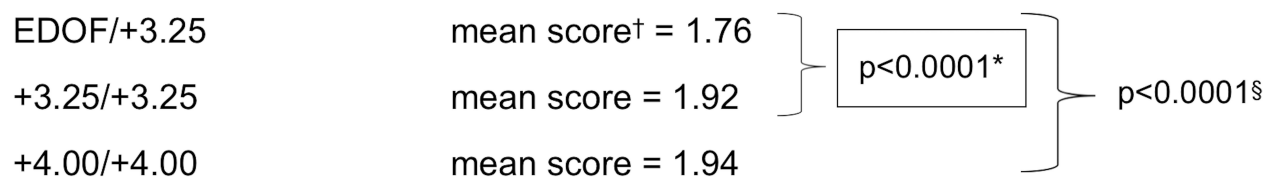

Figure $5 \mathrm{EDOF} /+3.25$ vs $+3.25 /+3.25$ vs $+4.00 /+4.00$.

Notes: ${ }^{\dagger}$ Scores: +2 None of the time; + I Some of the time; 0 Half of the time; - I Most of the time; -2 All of the time. *Significantly in favor of $+3.25 /+3.25$ vs $+3.25 / E D O F$. §Significantly in favor of $+4.00 /+4.00$ vs $+3.25 /$ EDOF.

"Ability to work on computer"

$\mathrm{EDOF} /+3.25$

$+3.25 /+3.25$

$+4.00 /+4.00$

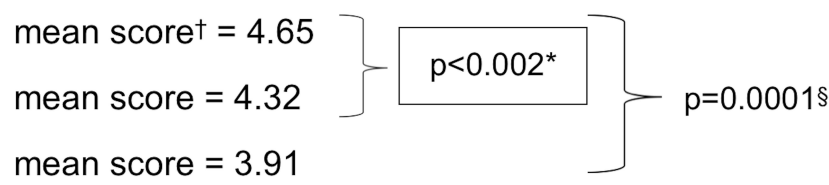

Figure $6 \mathrm{EDOF} /+3.25$ vs $+3.25 /+3.25$ vs $+4.00 /+4.00$.

Notes: ${ }^{\dagger}$ Scores: 5 Excellent; 4 Very Good; 3 Good; 2 Fair; I Poor. *Significantly in favor of EDOF/+3.25 vs $+3.25 /+3.25$. ${ }^{\S}$ Significantly in favor of EDOF/+3.25 vs $+4.00 /+4.00$.

"Ability to see far away"

$\mathrm{EDOF} /+3.25$

$+3.25 /+3.25$

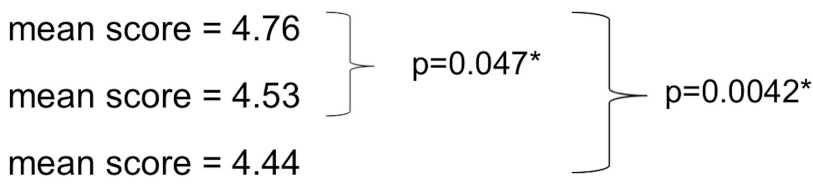

$+4.00 /+4.00$

Figure $7 \mathrm{EDOF} /+3.25$ vs $+3.25 /+3.25$ vs $+4.00 /+4.00$.

Notes: *EDOF/+3.25 significantly better vs $+3.25 /+3.25$ and $+4.00 /+4.00$. 
$(p=0.002)$ in the $+3.25 /+3.25$ cohort which was already significantly better than the $+4.00 /+4.00$ cohort $(p=0.02)$.

The results for the variable of "ability to see far away" demonstrated superior distance vision for the EDOF/ +3.25 cohort (Table 3). The grade of excellent increases to $80 \%$ in the EDOF/ +3.25 cohort compared to $56 \%$ and $66 \%$ in the $+4.00 /+4.00$ and $+3.25 /+3.25$ cohorts, respectively. The mean score of $4.76 / 5.00$ is significantly superior $(\mathrm{p}=0.047)$ to both other cohorts.

The objective data for 8 preoperative and 13 postoperative variables are presented in Table 4 .

\section{Discussion}

The purpose of this investigation was to detect which patient variables contribute significantly to "overall patient satisfaction" using multivariate regression analysis for three different bilateral cohorts of presbyopic correcting IOLs. The IOLs implanted in these three cohorts trace the evolution of available presbyopic IOLs in the United States over the past 10 years from "high add" multifocal IOLs, to "low add" multifocal IOLs, to extended depth of focus IOLs.

Regression successfully identified intermediate vision as a vulnerable characteristic of the +4.00 "full add" IOLs (Figure 1). The percentage of patients rating their overall satisfaction as "very satisfied" increased significantly from $64 \%$ to $82 \%(\mathrm{p}=0.01)$ (Table 3$)$ in the bilateral +3.25 cohort compared to the bilateral +4.00 cohort. It is clinically intuitive that two moderate "low add" +3.25 IOLs will produce better intermediate vision than two "high add" +4.00 IOLs. However, it is not clinically intuitive that some +4.00 Tecnis multifocal IOLs produced excellent intermediate vision while others produced relatively poor uncorrected intermediate vision.

Interestingly, regression analysis detected pupil size as a strong predictor of overall patient satisfaction (Figures 2 and 8). The smaller the mesopic pupil size the greater the patient satisfaction because of its effect on intermediate vision. Regression analysis predicted that those patients with relatively smaller preoperative mesopic pupils chose "very satisfied" as their response on the questionnaire while those with relatively larger pupils chose only "satisfied". Regression analysis of the bilateral +3.25 cohort also revealed that this phenomenon is also intact for the +3.25 Tecnis multifocal IOL (Figure 3). Despite the generalized increase in intermediate function for the +3.25 IOL versus the +4.00 IOL because the focal distance increases from $33 \mathrm{~cm}$ to $42 \mathrm{~cm}$, those patients with smaller pupils in the bilateral +3.25 cohort had a statistically significant greater increase in intermediate vision compared to other patients in the bilateral +3.25 cohort because of the IOL design.

This study is the first to report the strong predictive correlation between preoperative mesopic pupil size and uncorrected postoperative intermediate vision. The center of the optic of all three TECNIS multifocal implants contain a $1.00 \mathrm{~mm}$ central area which has an optical power that is one half the power of the full add of the implant. The central $1.00 \mathrm{~mm}$ button of the +4.00 TECNIS multifocal implant has a power of $+2.00 \mathrm{D}$ in the IOL plane. Our data indicates that a decreasing mesopic pupil predicts and demonstrates improved intermediate vision. This phenomenon is not observed for distance or near vision, which we would expect from a pure pinhole effect.

We hypothesize that as the pupil decreases in size, a greater percentage of the light passing through the pupil is passing through the $1.00 \mathrm{~mm}$ central "button" and this enhances intermediate vision. Subsequent to our findings, the manufacturer released results from their IDE trial for the one-piece $+4.00 \mathrm{D}$ multifocal IOL, and the data is entirely consistent with our findings of increasing intermediate vision with decreasing pupil size with no significant effect on distance or near vision (Figure 8). It also makes intuitive sense that as the centration of the central $1.00 \mathrm{~mm}$ zone improves, the efficiency of the enhanced intermediate vision would increase, as revealed by the regression results (Figure 2).

We have established that preoperative pupil size is a meaningful predictor of postoperative uncorrected intermediate visual acuity with Tecnis multifocal IOLs. The availability of this knowledge for incorporation into the surgeon's preoperative strategy would have been invaluable when implanting the +4.00 Tecnis multifocal IOL since 2009 and the +3.25 Tecnis multifocal IOL since 2015. Chang et $\mathrm{al}^{5}$ reported better uncorrected intermediate vision under photopic versus mesopic lighting conditions for the +4.00 Tecnis (ZMB00) IOL, but did not study the effects of preoperative pupil size on postoperative vision.

Refractive cataract surgeons are seeking to maximize uncorrected distance, intermediate, and near vision. It is not unusual that one visual target must be sacrificed to improve another visual target. The increased overall patient satisfaction of the bilateral +3.25 cohort versus the bilateral +4.00 cohort did not occur just because of improved intermediate vision for the bilateral +3.25 cohort. The increased satisfaction is also supported by an 
increase in intermediate vision without an accompanying decrease or trade-off of near vision. So moving the focal distance from 14" to 17 " contributed significantly to improving intermediate visual function (Table 4), but this occurred while patients simultaneously perceived no drop off in their uncorrected near vision (Table 3).
This study demonstrated that, for appropriately selected patients, mixing different types of presbyopic correcting IOLs could achieve very high levels of patient satisfaction. The EDOF/+3.25 cohort demonstrated superior bilateral uncorrected distance (Figure 7) and intermediate vision (Figure 6). These advantages observed by the patients in

Table 4 Comparison of Outcomes Between Cohorts

\begin{tabular}{|c|c|c|c|c|c|c|}
\hline \multirow[t]{2}{*}{ Parameter } & \multicolumn{3}{|l|}{ Mean \pm SD } & \multicolumn{3}{|l|}{ P value } \\
\hline & $+4.00 /+4.00$ & $+3.25 /+3.25$ & $+3.25 /$ EDOF & $\begin{array}{l}+4.00 /+4.00 \\
\text { vs }+3.25 / \\
+3.25\end{array}$ & $\begin{array}{l}+4.00 /+4.00 \\
\text { vs }+3.25 / \\
\text { EDOF }\end{array}$ & $\begin{array}{l}+3.25 /+3.25 \\
\text { vs }+3.25 / \\
\text { EDOF }\end{array}$ \\
\hline $\begin{array}{l}\text { PreOp Mesopic Pupil } \\
(\mathrm{mm}) \mathrm{OU}\end{array}$ & $4.854 \pm 0.93459$ & $4.839 \pm 0.85949$ & $5.046 \pm 0.97627$ & 0.9281 & 0.2985 & 0.2351 \\
\hline $\begin{array}{l}\text { PreOP Photopic Pupil } \\
(\mathrm{mm}) \text { OU }\end{array}$ & $3.429 \pm 0.68745$ & $3.503 \pm 0.70339$ & $3.632 \pm 0.79048$ & 0.5714 & 0.1757 & 0.1719 \\
\hline $\begin{array}{l}\text { PreOP Spherical } \\
\text { Equivalent OU }\end{array}$ & $-1.36 \pm 3.62985$ & $-0.77 \pm 3.03661$ & $-1.39 \pm 3.53444$ & 0.3294 & 0.9167 & $0.0396 *$ \\
\hline $\begin{array}{l}\text { PostOp UDVA (Snellen) } \\
\text { OU }\end{array}$ & $20 / 22 \pm 2.981$ & $20 / 20.76 \pm 1.806$ & $20 / 20 \pm 1.667$ & $0.0057^{*}$ & $<0.001 *$ & $0.0197 *$ \\
\hline $\begin{array}{l}\text { PostOp Spherical } \\
\text { Equivalent OU }\end{array}$ & $0.025 \pm 0.27692$ & $-0.036 \pm 0.21891$ & $-0.027 \pm 0.23821$ & 0.8042 & 0.2887 & 0.8411 \\
\hline PostOp Astigmatism OU & $0.3455 \pm 0.22944$ & $0.44 \mid 3 \pm 0.22168$ & $0.2955 \pm 0.25295$ & $0.0215^{*}$ & 0.3363 & $0.0015^{*}$ \\
\hline $\begin{array}{l}\text { PostOp BDVA (Snellen) } \\
\text { OU }\end{array}$ & $20 / 20.18 \pm 0.945$ & $20 / 20.08 \pm 0.615$ & $20 / 18.91 \pm 2.344$ & $0.485 I$ & $0.0006^{*}$ & $0.0004^{*}$ \\
\hline $\begin{array}{l}\text { PostOp UNVA Letters } \\
\text { Read OU }\end{array}$ & $98.56 \pm 4.936$ & $97.80 \pm 4.655$ & $98.78 \pm 3.606$ & 0.3860 & 0.9042 & 0.2686 \\
\hline $\begin{array}{l}\text { PostOp UNVA Patients } \\
\text { Best Distance }(\mathrm{cm}) \text { OU }\end{array}$ & $38.04 \pm 3.41$ & $38.26 \pm 5.37$ & $40.48 \pm 4.73$ & 0.7932 & $0.003 I^{*}$ & $0.0219 *$ \\
\hline $\begin{array}{l}\text { PostOp UIVA at Fixed } \\
\text { Distance } 63 \mathrm{~cm} \text { Letters } \\
\text { Read OU }\end{array}$ & $90.20 \pm 6.32$ & $97.21 \pm 4.32$ & $99.69 \pm 3.54$ & $<0.000 I^{*}$ & $<0.000 I^{*}$ & $0.0012^{*}$ \\
\hline $\begin{array}{l}\text { PostOp UIVA Patients } \\
\text { Best Distance Letters } \\
\text { Read OU }\end{array}$ & $94.58 \pm 6.620$ & $101.77 \pm 5.414$ & $103.46 \pm 3.66$ & $<0.000 I^{*}$ & $<0.000 I^{*}$ & $0.0427^{*}$ \\
\hline $\begin{array}{l}\text { PostOp UIVA Patients } \\
\text { Best Distance }(\mathrm{cm}) \text { OU }\end{array}$ & $59.74 \pm 2.654$ & $54.38 \pm 7.402$ & $54.63 \pm 7.58$ & $<0.0001 *$ & $<0.000 I^{*}$ & 0.9480 \\
\hline $\begin{array}{l}\text { PostOp Reading Acuity } \\
\text { (LogMAR) OU }\end{array}$ & $0.004364 \pm 0.08796$ & $-0.04136 \pm 0.08572$ & $-0.05491 \pm 0.09418$ & $0.0212^{*}$ & $0.0014^{*}$ & 0.5007 \\
\hline $\begin{array}{l}\text { PostOp Reading Acuity } \\
\text { Patients Best Distance (cm) }\end{array}$ & $39.20 \pm 2.0763$ & $39.97 \pm 5.3117$ & $41.95 \pm 3.8558$ & 0.3136 & $<0.000 I^{*}$ & $0.0313^{*}$ \\
\hline $\begin{array}{l}\text { PostOp Reading Speed } \\
\text { OU (WPM) }\end{array}$ & $82.34 \pm 37.278$ & $78.09 \pm 46.935$ & $75.91 \pm 22.053$ & 0.5995 & 0.2765 & 0.7435 \\
\hline $\begin{array}{l}\text { PostOp Reading Speed } \\
\text { Patients Best Distance } \\
(\mathrm{cm}) \mathrm{OU}\end{array}$ & $39.28 \pm 2.12891$ & $40.21 \pm 5.28427$ & $41.64 \pm 3.48735$ & 0.2431 & $0.0001 *$ & 0.0563 \\
\hline Angle Kappa OU & $0.2868 \pm 0.1156$ & $0.294 I \pm 0.1264$ & $0.2880 \pm 0.1249$ & 0.7628 & 0.9838 & 0.7449 \\
\hline RMS Factor OU & $0.6051 \pm 0.24965$ & $0.5478 \pm 0.19341$ & $0.6129 \pm 0.29325$ & 0.1912 & 0.8207 & 0.1488 \\
\hline Trefoil OU & $0.1777 \pm 0.0935$ & $0.1462 \pm 0.0757$ & $0.1735 \pm 0.1189$ & 0.0607 & 0.9222 & 0.1291 \\
\hline Coma OU & $0.1396 \pm 0.0744$ & $0.1166 \pm 0.0571$ & $0.1492 \pm 0.0926$ & 0.0782 & 0.5038 & $0.0227^{*}$ \\
\hline Spherical Aberrations OU & $-0.0003 \pm 0.04502$ & $-0.0062 \pm 0.05223$ & $0.0216 \pm 0.06948$ & 0.5410 & 0.0586 & $0.0187^{*}$ \\
\hline
\end{tabular}

Note: *Statistical significance defined as $p<0.05$. 


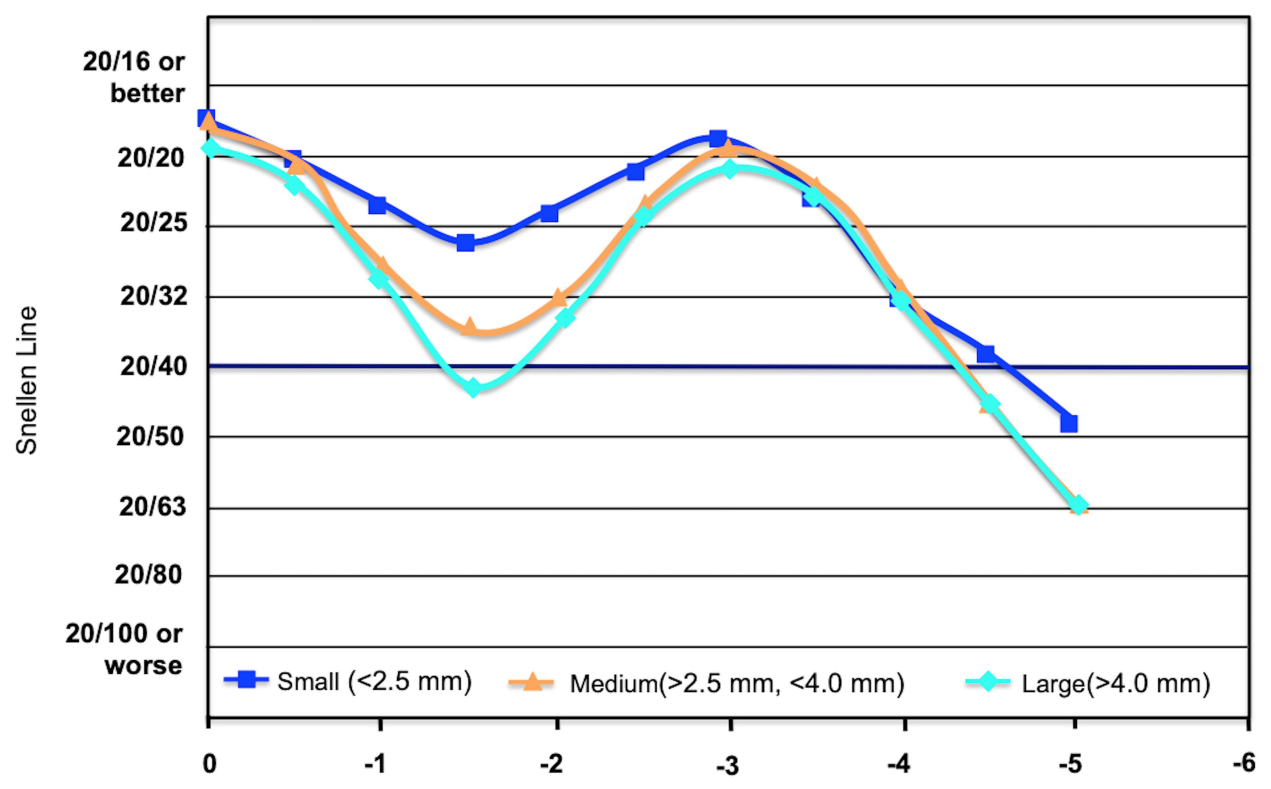

Figure 8 TECNIS $^{\circledR}$ Multifocal I-Piece Defocus Curve.

the EDOF/+3.25 cohort appear to have outweighed perceived disadvantages with uncorrected near vision when reading fine print. Significant differences for near vision with moderately sized print were not observed. The achromatic optics of the Symfony IOL may be a factor explaining the superior distance vision in the EDOF/ +3.25 cohort. The extended depth of focus and the low add of +1.75 for the Symfony IOL help explain the superior intermediate vision observed by the patients in this cohort.

A small number of other authors ${ }^{6-10}$ have described successful outcomes when mixing different types of presbyopic IOLs. Black ${ }^{6}$ reported the binocular results of 50 patients receiving an EDOF (Symfony) in the dominant eye and a Tecnis +3.25 multifocal IOL in the nondominant eye. Patients achieved high levels of uncorrected acuity at all focal distances with 97\% 20/25 or better at distance, 97\% 20/ 25 or better for intermediate, and $94 \%$ had $20 / 25$ or better at near.

De Medeiros et $\mathrm{al}^{7}$ compared the bilateral results of a combination of an EDOF (Symfony) with a +4.00 Tecnis multifocal IOL versus the bilateral implantation of the Panoptic trifocal IOL. Although both groups (10 patients in both groups) provided reasonably good functional vision over all focal distances, the mixed group showed better contrast sensitivity without glare under both photopic and mesopic conditions. The defocus curve for the mixed cohorts showed significantly better performance at -1.50 and -3.00 , but the trifocal combination was better at -2.00 .
Venter et $\mathrm{al}^{8}$ compared three combinations of presbyopic IOLs in over 5000 patients. Group A received two +2.75 Tecnis multifocal IOLs, group B received an EDOF Tecnis Symfony in the dominant and a +2.75 Tecnis multifocal in the nondominant eye, and group $\mathrm{C}$ received an EDOF Tecnis Symfony in the dominant eye and $\mathrm{a}+3.25$ in the nondominant eye. Uncorrected near visual acuity was superior in the Symfony/+3.25 group (group C). Group $\mathrm{C}$ also had the highest levels of patient satisfaction but the differences among groups were not statistically significant.

Yang et $\mathrm{al}^{9}$ demonstrated that mixing two bifocal IOLs with different add powers can achieve high levels of functional success. They placed the Tecnis +2.75 multifocal in the dominant eye and the Tecnis +3.25 in the nondominant eye. Ninety-five percent of patients did not require glasses for near and intermediate vision. ${ }^{8}$

Bissen-Miyajima et $\mathrm{al}^{10}$ also compared three groups of patients with mixed presbyopic IOLs. All groups received $\mathrm{a}+4.00$ Tecnis in their first eye. Each of the three groups then received a $+4.00, a+3.25$, or $\mathrm{a}+2.75$ Tecnis in their second eye, respectively. As observed in our study, the bilateral +4.00 group had a statistically inferior intermediate vision compared to the cohorts with lower-add IOLs.

A limitation of our report is that each cohort was not prospectively created at the same time. However, the methods and multivariate regression model were identical for all three cohorts. Another weakness could be that we failed to directly test contrast sensitivity. If there were 
significant differences in contrast sensitivity, it could have been indirectly accounted for by the patient responses for overall satisfaction on the questionnaire. If it had been included as an objective metric, regression may have been able to detect if it contributed significantly to responses regarding overall satisfaction.

A strength of our study is the large number of bilateral patients in each of our three cohorts. The large number of bilateral presbyopic IOL patients in each cohort only serves to reinforce the strength of our unique regression model and its ability to detect and quantify variables responsible for overall patient satisfaction.

In summary, our report demonstrated that (1) bilateral moderate-add multifocal IOLs perform better than bilateral high-add multifocal IOLs due to superior intermediate vision in the moderate-add IOL patients (2) mixed EDOF and moderate-add IOL patients can achieve very high levels of patient satisfaction if individual patient characteristics and visual needs are matched to the optical characteristics of the presbyopic correcting implants (3) all Tecnis multifocal implants achieve significantly greater uncorrected intermediate vision in patients with small pupils above and beyond the pinhole effect, and (4) multivariate regression analysis can be an effective tool for detecting patient characteristics and objective variables that determine their quantifiable postoperative levels of overall patient satisfaction.

\section{Disclosure}

The author has received financial support for the conduct of this study from Johnson \& Johnson Vision, Jacksonville, FL, USA, receives financial support from Johnson \& Johnson Vision for the conduct of Investigator-
Initiated studies, outside this work, and reports no other potential conflicts of interest for this work.

\section{References}

1. de Silva DR, Evans JR, Kirthi V, Ziaei M, Leyland M. Multifocal versus monofocal intraocular lenses after cataract extraction. Cochrane Database Syst Rev. 2016;(12):CD003169.

2. Poyales F, Garzon N. Poyales, comparison of 3-month visual outcomes of a spherical and a toric trifocal intraocular lens. J Cataract Refract Surg. 2019;45(2):135-145. doi:10.1016/j.jcrs.2018.09.025

3. Kohnen T. Questionnaires for cataract and refractive surgery. J Cataract Refract Surg. 2019;45(2):119-120. doi:10.1016/j.jcrs.20 18.12 .020

4. Monaco G, Gari M, Di Censo F, Poscia A, Ruggi G, Scialdone A. Visual performance after bilateral implantation of 2 new presbyopia-correcting intraocular lenses: trifocal versus extended range of vision. J Cataract Refract Surg. 2017;43(6):737-747. doi:10.1016/j.jcrs.2017.03.037

5. Chang D. Visual acuity and patient satisfaction at varied distances and lighting conditions after varied implantation of an aspheric diffractive multifocal one-piece intraocular lens. Clin Ophthalmol. 2016;10:1471-1477. doi:10.2147/OPTH.S108298

6. Black S. A clinical assessment of visual performance of combining the TECNIS ${ }^{\circledR}$ symfony extended range of vision IOL (ZXR00) with the +3.25 D TECNIS Multifocal 1-piece IOL (ZLB00) in subjects undergoing bilateral cataract extraction. Clin Ophthalmol. 2018; 12:2129. doi:10.2147/OPTH.S175901

7. de Medeiros AL, de Araújo Rolim AG, Motta AFP, et al. Comparison of visual outcomes after bilateral implantation of a diffractive trifocal intraocular lens and blended implantation of an extended depth of focus intraocular lens with a diffractive bifocal intraocular lens. Clin Ophthalmol. 2017;11:1911-1916. doi:10.2147/OPTH.S145945

8. Venter J, EDOF IOL in Patients with Previous Laser Correction, ePoster, ESCRS. 2019.

9. Yang CM, Lim DH, Hwang S, Hyun J, Chung T-Y. Prospective study of bilateral mix-and-match implantation of diffractive multifocal intraocular lenses in Koreans. BMC Ophthalmol. 2018;18:73. doi:10.1186/s12886-018-0735-0

10. Bissen-Miyajima H, Ota Y, Nakamura K, Hirasawa M, Minami K. Binocualr visual function with staged implantation of diffractive multifocal intraocular lenses with three add powers. Am J Ophthalmol. 2019;199:223-229. doi:10.1016/j.ajo.2018.11.020
Clinical Ophthalmology

\section{Publish your work in this journal}

Clinical Ophthalmology is an international, peer-reviewed journal covering all subspecialties within ophthalmology. Key topics include: Optometry; Visual science; Pharmacology and drug therapy in eye diseases; Basic Sciences; Primary and Secondary eye care; Patient Safety and Quality of Care Improvements. This journal is indexed on PubMed

Submit your manuscript here: https://www.dovepress.com/clinical-ophthalmology-journal
Central and CAS, and is the official journal of The Society of Clinical Ophthalmology (SCO). The manuscript management system is completely online and includes a very quick and fair peer-review system, which is all easy to use. Visit http://www.dovepress.com/ testimonials.php to read real quotes from published authors. 